\title{
Research on over current switch-off simulation of IGBT level in parallel connection
}

\author{
Ge Zhao ${ }^{1,2 a}$, Mingchao Gao ${ }^{1, a}$,Yaohua Wang ${ }^{1,2 a}$, Jiang Liu ${ }^{1, a}$, \\ Rui Jin $^{1,2 a}$ Jialiang Wen ${ }^{1,2 a}$ \\ ${ }^{1}$ Power Electronics Department, State Grid Smart Grid Research Institute, Chang Ping District \\ Beijing China 100192. \\ ${ }^{2}$ State Key Laboratory of Advanced Power Transmission Technology, State Grid Smart Grid \\ Research Institute, Chang Ping District Beijing China 100192. \\ azhaoge@sgri.sgcc.com.cn
}

Keywords: IGBT; Parallel Connection; Switch-Off; RBSOA; Simulation; Over Current Abstract: IGBT chips are basic structure of power electronic devices in the power grid system. The IGBT module with high current capability needs multi chips parallel connection. Because there are different performance parameters of the IGBT chips in the Wafer, it is necessary to select the parameters of the IGBT chips for the IGBT modules to make the performance parameters of chips as consistent as possible. However, it is unknown that what the influence of performance parameter differences between IGBT chips on the overall performance of the module such as IGBT modules' switch-off and RBSOA characteristics is. In addition, switching state of each single IGBT chip is not monitored when the whole module is on working state. This paper is trying to demonstrate a method to research the multi parallel chips on the performance of different parameters effects of each single IGBT chip switch-off Process, which is based on the T-CAD software tool.

\section{Introduction}

For high-power applications, rated currents of power devices usually have several thousand amperes unit. To realize such a large rated current, many IGBT chips, typically more than 10 and even more are connected in parallel. In an ideal case the current capability of IGBT chips scales with the number of chips connected in parallel. A perfect current sharing is not realistic because of a never completely matched impedance of each chip connection and parameter variations between the different chips. In addition, unequal performance parameters of the semiconductor devices can lead to further current imbalance in and between the IGBTs. However, the research literature on the parallel characteristics of IGBT chip and the related problems are few. When the IGBT chip once sealed module, it's difficult to monitor the single chip of IGBT module in the working state, especially switch-off state. If the chip performance parameters is not unequal, it will reduce the whole IGBT module's RBSOA and robust[1]. This paper is trying to provide a method to research the effects of different parameters of each IGBT chips on the performance of the multi parallel chips in switch-off process.

\section{Device structure and simulation spice setup}

The device under simulation is a $1.2 \mathrm{kV} / 75$ A NPT IGBT. As shown in Fig.1, the active area of device of is $1 \mathrm{~cm} 2$ and the starting material is $\mathrm{N}$-type float zone silicon, using the plane-gate structure. In addition, Substrate thickness is from 160um to 200um. 


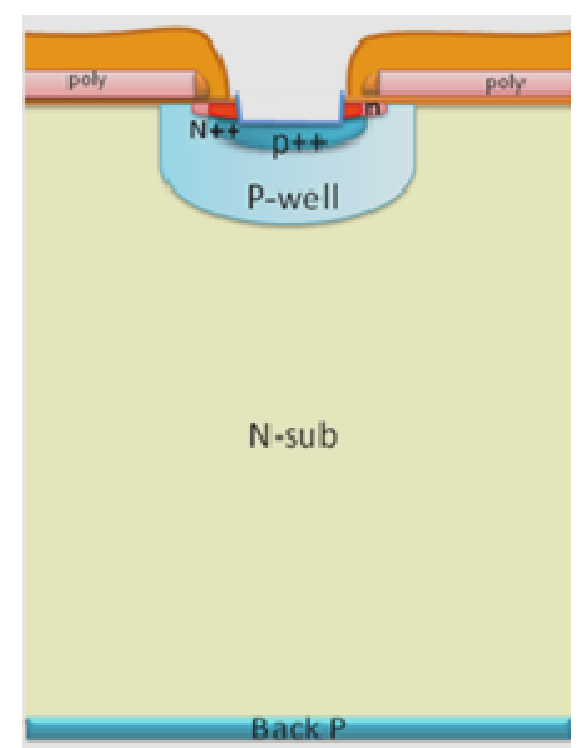

Fig 1. 1.2 kV/75 A NPT IGBT Chip Profile structure.

The simulation set-up with three IGBTs in parallel strings is shown as Fig.2. The mutual connections among electrodes of the three IGBT chips are implemented using the device structure editor software T-CAD. And Simulation of the switch-off process of three IGBTs devices is achieved by the timing and electrical characteristics of editing control. All the time series and the electrical characteristics of the control are added to the bus terminal in parallel with the three IGBT chips. So it can be used to simulate the three IGBTs as a whole module in the switch-off state. At the same time, it is possible to reduce the parasitic parameters and avoid the effects of the IGBT device itself. The purpose is to obtain the pure device performance parameters in the switch-off situation[2].

Simulation conditions:

$$
\begin{aligned}
& \text { Tvj }=25^{\circ} \mathrm{C}, \\
& \mathrm{IC}=450 \mathrm{~A}, \\
& \mathrm{VCE}=600 \mathrm{~V}, \\
& \mathrm{VGE}= \pm 15 \mathrm{~V}, \\
& \text { RG }=6 \Omega .
\end{aligned}
$$

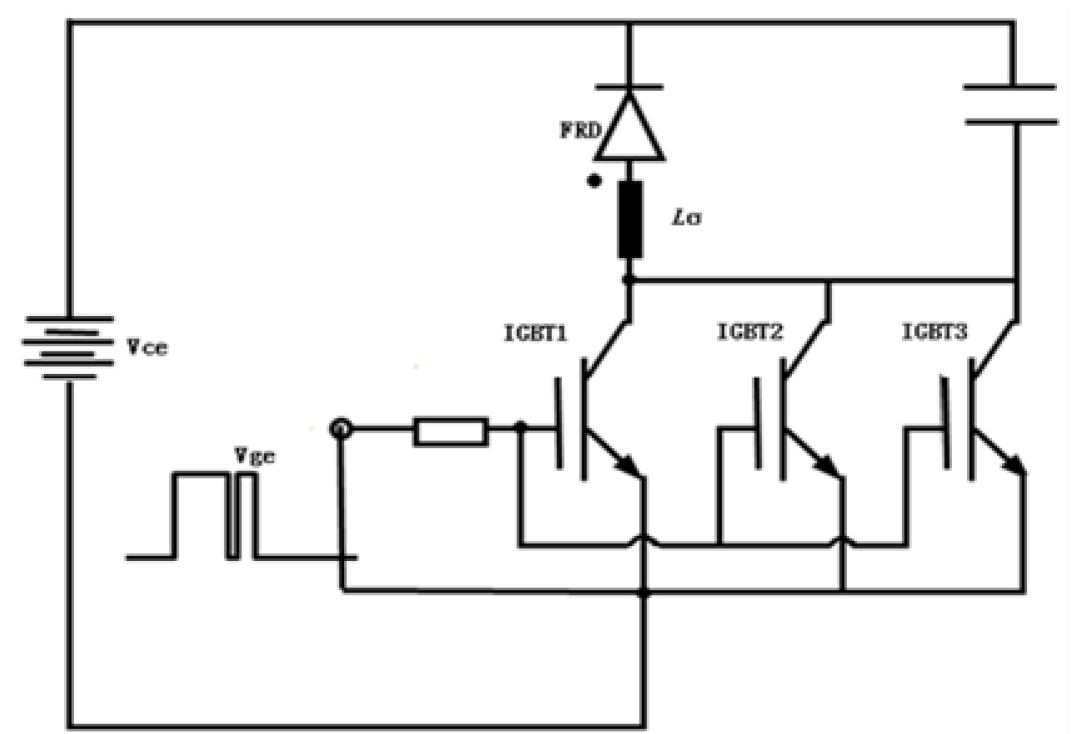

Fig 2. Simulation set-up with three IGBTs in parallel strings. 


\section{Results and discussion}

The simulation of the 2 times of the rated current switch-off characteristics (RBSOA) for the 3 parallel IGBT chip is carried out in this paper. The simulation of the parallel chip is carried out Module stray inductance.

The module stray inductance is typically in the range of $50 \mathrm{nH}[3]$ for classical module designs. For more advanced packages, this value is reduced to $10-20 \mathrm{nH}$ [3]. The difference parameters of the IGBT device are shown in Table 1, and the other parameters are identical. Fig. 3 shows the influence of Module stray inductance parameters on switch off current of the three parallel IGBT chips.

Table 1. The three parallel IGBT chips parameters

\begin{tabular}{|l|l|l|l|l|}
\hline Parameter & $\begin{array}{l}\text { P-well } \\
\text { concentration }\end{array}$ & $\begin{array}{l}\text { Back-P+ } \\
\text { concentration }\end{array}$ & Vce.sat & Vth \\
\hline IGBT1 & $105 \% \mathrm{~A}$ & $105 \% \mathrm{~B}$ & 2.576 & 5.931 \\
\hline IGBT2 & $\mathrm{A}$ & $\mathrm{B}$ & 2.592 & 5.907 \\
\hline IGBT3 & $95 \% \mathrm{~A}$ & $95 \% \mathrm{~B}$ & 2.608 & 5.882 \\
\hline Unit & $/ \mathrm{cm} 3$ & $/ \mathrm{cm} 3$ & $\mathrm{~V}$ & $\mathrm{~V}$ \\
\hline
\end{tabular}

According to the simulation results, the increase of stray inductance leads to the increase of peak voltage as well as the IGBT induced current [4]. Besides, The current of the IGBT1 is twice more than the rated current, when the stray inductance is significantly increased. It is likely to cause IGBT1 over current failure, thereby destroying the whole module [5].

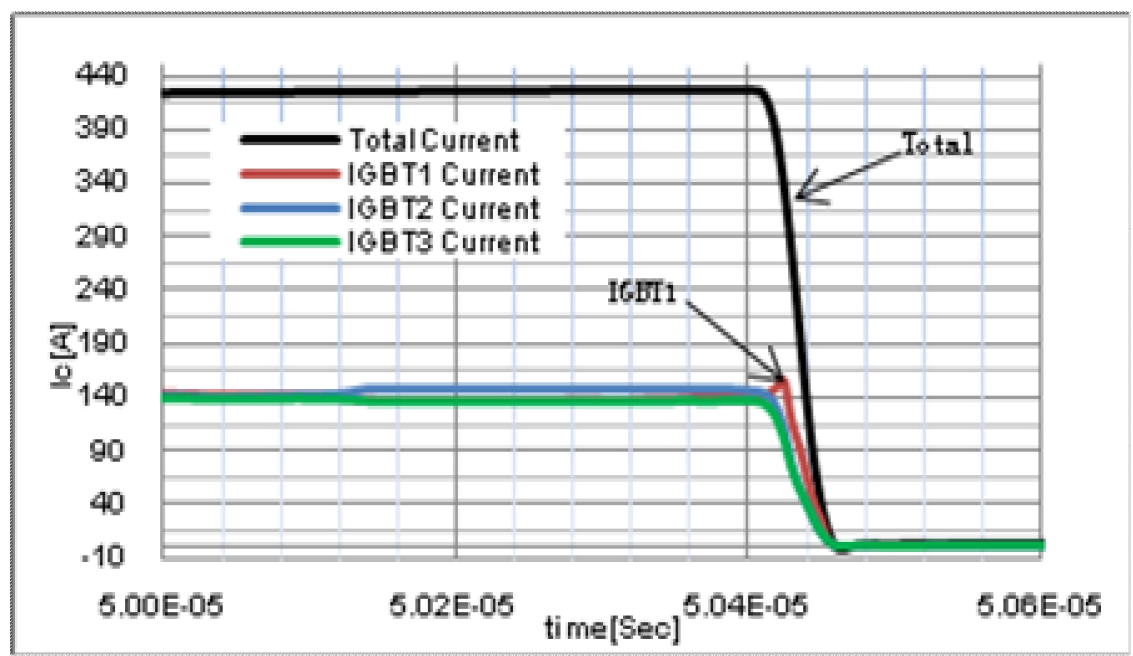

Fig 3. The influence of Module stray inductance parameters on switch off current of the three parallel IGBT chips, $L \sigma=20 \mathrm{nH}$. 


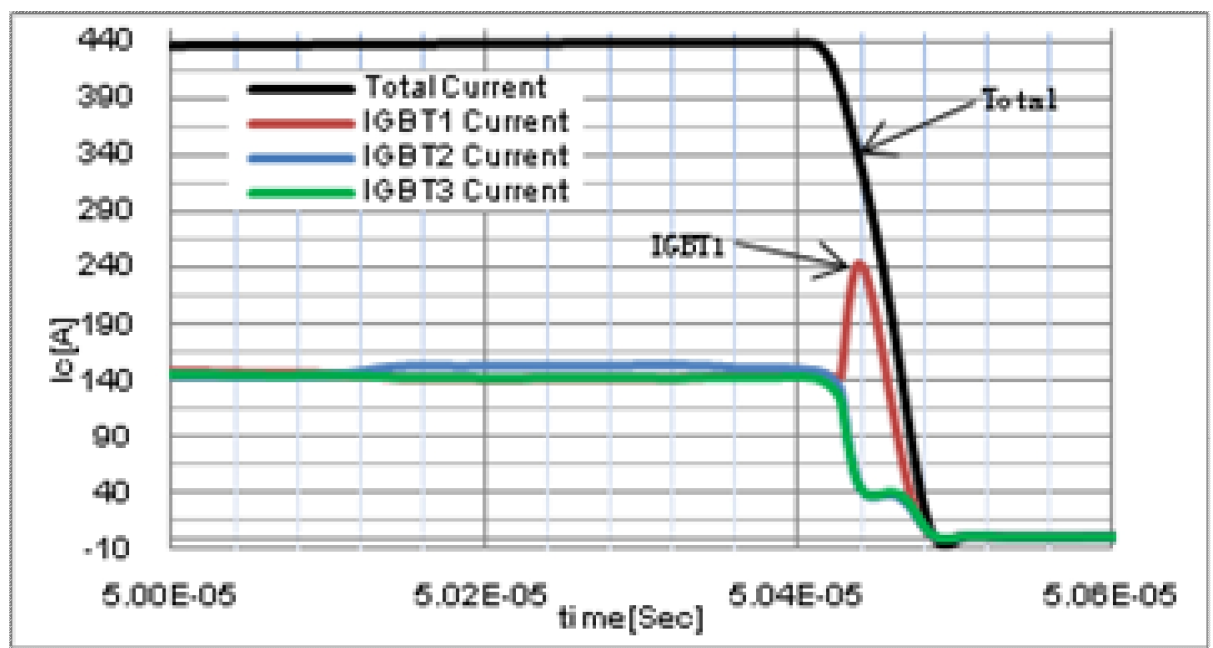

Fig 4. The influence of Module stray inductance parameters on switch off current of the three parallel IGBT chips, $L \sigma=50 \mathrm{nH}$.

\section{Conclusions}

In summary, the simulation results of the double rated current switch-off characteristics (RBSOA) for the 3 parallel IGBT chips are carried out in this paper The simulation mainly included this aspect: Module stray inductance the corresponding results were shown as figures, which could help select chips in wafer Level for high current module package.

\section{Acknowledgements}

This work was financially supported by d by the State Grid Corporation of Technology Special Project <3300V/1200A Soft Punch Though IGBT Module Research>(No. SGRI-WD-14-005).

\section{References}

[1] Dieter k. Semiconductor Material and Device Characterization A JOHN WILEY \& SONS, INC.,2006

[2] Tsuneo OguraHigh. Turn-Off Current Capability of Parallel-Connected 4.5 kV Trench IEGT.IEEE TRANSACTIONS ON ELECTRON DEVICES, VOL. 50, NO. 5, MAY 2003

[3] Josef Lutz .Semiconductor Power Devices-Physics, Characteristics, Reliability Springer, 2008

[4] Jörg Berner. Application Note I Paralleling of IGBT modules ABB Switzerland Ltd. Technical publications 2008

[5] KONG Liang,Research and Measurement of Chip CurrentImbalance in IGBT Module with Multiple Chips in Parallel.2013 International Conference on Electrical Machines and Systems, Oct. 26-29, 2013, Busan, Korea 